\title{
Depression in Racial and Ethnic Minorities: the Impact of Nativity and Discrimination
}

\author{
Henna Budhwani • Kristine Ria Hearld • \\ Daniel Chavez-Yenter
}

Received: 22 April 2014 / Revised: 23 July 2014 / Accepted: 22 August 2014 / Published online: 11 September 2014

(C) W. Montague Cobb-NMA Health Institute 2014

\begin{abstract}
This research examines factors associated with lifetime major depressive disorder in racial and ethnic minorities residing in the USA, with an emphasis on the impact of nativity, discrimination, and health lifestyle behaviors. The Healthy Migrant Effect and Health Lifestyle Theory were used to inform the design of this project. The use of these frameworks not only provides insightful results but also expands their application in mental health disparities research. Logistic regression models were implemented to examine risk factors associated with lifetime major depressive disorder, comparing immigrants to their American-born counterparts as well as to American-born Whites. Data were derived from the Collaborative Psychiatric Epidemiology Surveys ( $n=$ 17,249). Support was found for the hypothesis that certain immigrants, specifically Asian and Afro-Caribbean, have lower odds of depression as compared their non-immigrant counterparts. Although, Hispanic immigrants directionally had lower odds of depression, this finding was not statistically significant. Furthermore, engaging in excessive alcohol consumption was associated with higher rates of depression (odds
\end{abstract}

H. Budhwani $(\bowtie)$

Department of Health Care Organization and Policy, University of Alabama at Birmingham, 1665 University Boulevard, Birmingham, AL 35294, USA

e-mail: budhwani@uab.edu

K. R. Hearld

Department of Health Services Administration, University of Alabama at Birmingham, 1705 University Boulevard, Birmingham, AL 35294, USA

e-mail:khearld@uab.edu

H. Budhwani • D. Chavez-Yenter

University of Alabama at Birmingham, UAB Sparkman Center for Global Health, 1665 University Boulevard, Birmingham,

AL 35294, USA

D. Chavez-Yenter

e-mail: chavezye@uab.edu ratio $(\mathrm{OR})=2.09, \mathrm{p}<0.001)$, and the effect of discrimination on depression was found to be significant, even when controlling for demographics. Of all racial and ethnic groups, foreign-born Afro-Caribbeans had the lowest rate of depression at $7 \%$ followed by foreign-born Asians at $8 \%$.

Keywords Health paradox · Depression · Immigrants · Discrimination $\cdot$ Nativity

\section{Introduction}

Since 2000, there has been rapid growth of minorities in the USA; these groups now comprise more than one third of the overall population [1], with projections of becoming the majority by 2050 [2]. Minority health is a significant contributor to overall population health, making it necessary for researchers and public health practitioners to understand causes and correlates of health outcomes, such as depression in these groups. Thus, the aim of this study is to evaluate correlates of major depressive disorder (henceforth depression) in racial and ethnic minorities residing in the USA.

A myriad of factors, which affect minorities, interact leading to the outcome of depression. Race, which is based on biological markers; ethnicity, which reflects an ancestry; social, cultural, or national experience; and nativity (birth place-foreign or domestic) are known influencers [3-6]. Studies have found that Blacks have similar or better mental health than Whites regardless of economic disadvantages and discrimination [7-10]. Among Hispanic women, Asian women, and Black women, mental illness rates are lower than those of White women; following the same trend, Hispanic, Asian, and Black men rates of mental illness are generally lower than those of White men [10-17]. Gender has also been directly correlated with the prevalence of depression; women are more likely to be depressed than men, but across gender and race, 
black women through self-salience (relative importance of the self and others in social relations) have more protective factors against depression than White women [17]. Gender and race effects on self-salience and mental health are mediated by social class [17]. Not only are women less likely to suffer from depression compared to White women; black men are less depressed than White men in lower-education groups [17, 18]. Furthermore, immigrants (foreign-born) exhibit better physical and mental health outcomes as compared to their Americanborn counterparts [3-5]; this health paradox has been explained by the Healthy Migrant Effect (HME). The HME asserts that a selection bias exists which limits the ability of individuals to migrate who are in poorer health or have fewer social or economic resources $[3,5,19]$. This health advantage is mitigated by exposure to discrimination, which has consequences on mental health, such as increased rates of depression, increased stress levels, and increased rates of generalized anxiety [20-23].

Thus, this paper contributes to the existing body of health disparities research by offering a holistic analysis of correlates linked to depression in racial and ethnic minorities and leverages the HME in study design rather than applying it post facto to explain unanticipated outcomes. Demographic characteristics (age, gender), socioeconomic status (income, education), and health behaviors (alcohol consumption, smoking behavior) are included in our models. This research evaluates Blacks, Asians (racial classification), Afro-Caribbeans, and Hispanics (ethnic identifiers) with the intent of understanding effects of race and ethnicity separately.

\section{Background}

Historical disparities research indicates that women, some racial and ethnic minorities, persons with less than a high school education, those previously married, unemployed individuals, and persons without health care insurance coverage are more likely to have depression [23]. More recent work specifies more nuanced patterns across and within racial and ethnic minorities attributable to nativity, socioeconomic status, and other protective effects and risk factors [24-29]; therefore, all groups do not react the same way to the same stimuli. For our study, we elected to examine the groups, based on their ethnicity or race (Black and Asian as races, Hispanic and Afro-Caribbean as ethnicities) and place of birth (foreign-born as compared to American-born), including other measures known to influence depression, specifically lifetime major depressive disorder. At the most basic level, foreign-born immigrants typically exhibit lower rates of mental illnesses [3-5], which is often explained by the HME. The HME asserts that immigrants are healthier than the American-born due to structural forces and individual agency facilitating or hampering migration [3, 4]. The HME posits an immigrant health paradox; those who immigrate here are healthier than their American-born counterparts. Some researchers suggest that the paradox is a result of protective factors and social support unavailable to non-immigrants in addition to a selection bias, even when controlling for lower levels of education and income [24,30].

\section{Socioeconomic Status and Demographic Measures}

Socioeconomic status (SES) is predictive of overall physical and mental health; those with better physical health outcomes typically have a higher level of education and income [31, 32]. Cockerham [33] found that groups with lower education and income had the highest rates of mental disorders, including depression. Additionally, some research suggests that education and income have a direct effect on the mental health of racial and ethnic minorities and immigrants, reflecting the same trend found in the general public [34-36]. SES is particularly relevant to this project, because although immigrants often have lower levels of education and income as compared to American-born individuals, they also have lower levels of infirmity compared to American-born individuals. [36]. This project seeks to better understand the extent of education and income's relationship with depression controlling for nativity, in addition to demographic measures such as race, ethnicity, gender, and age.

Demographic measures have mixed effects on mental health outcomes. Age correlates with depression; the National Comorbidity Study found that the onset of mental illness (major depressive disorders as well as all mood disorders) was most likely to appear in the ages of 30-44 [37]. The average age of migration in the USA is very fluid but can be estimated to be between 29.4 and 35.9 years [38], and since the duration of stay increases depression risk, these age groups highlight the importance of the use of lifetime depression. Gender also has a direct influence on depression; women are more likely to be depressed than men, but when linking gender and race, Black women exhibit lower rates of depression than White women [17]. Although gender and ethnicity have been well-studied, the effects of the interrelationship of SES, demographics, nativity, and secondary risks (discrimination and health behaviors) on depression have not been fully assessed.

\section{Discrimination and Behavioral Factors}

Discrimination is the negative effect felt by one group due to their minority status that may occur at the individual level or may be embedded in a large societal structure and is meant to be harmful [20, 39]. Discrimination has well-documented negative consequences on mental health [20-22], and racial and ethnic minorities feel the effects of discrimination directly. However, American-born minorities report more experiences of discrimination compared to those foreign-born individuals [20, 40-42], due to heightened awareness or a different sense of social justice (compared to foreign-born), ultimately leading to a greater stress effect and higher rate of depression [21, 
$22,40]$. Consequently, although immigrants may engage in tobacco smoking and excessive alcohol consumption prior to migration, the intensity and frequency may increase as a response to discrimination and socioeconomic stress [43, 44].

The Health Lifestyle Theory (HLT), which asserts that excessive alcohol consumption and tobacco use (as well as other health behaviors) impact physical and mental health outcomes, has been included to inform the design of this analysis [43]. Specifically, cigarette smoking and excessive alcohol consumption have been correlated with increased levels of mental illness $[45,46]$. Although there is a decreasing trend of smoking and excessive alcohol consumption in foreign-born minorities as compared to their American-born counterparts, these behaviors still persist and are germane to the outcome of depression [47-51]. Furthermore, discrimination and demographic measures may moderate these relationships [20, 41].

Thus, using the HME and HLT to inform the design of this project, we compared the correlates of major depressive disorder across groups-(a) Hispanics, (b) Afro-Caribbean Blacks (Afro-Caribbeans), (c) African American Blacks (Blacks), and (d) Asians - to American-born Whites and their American-born racial and ethnic counterparts using data from the Collaborative Psychiatric Epidemiology Surveys (CPES). Potential predictive factors based on literature reviewed were included, specifically discrimination, nativity, ethnicity or race, gender, education, income, age, and health behaviors (smoking and alcohol consumption).

\section{Methods}

Data

The CPES, sponsored by the National Institute of Mental Health, is a repository of data with a special focus on race and ethnicity and mental health and illness. The CPES is a result of collaboratively developing and implementing three nationally representative surveys, each focusing on a different racial and/or ethnic minority group: the National Comorbidity Survey Replication (NCS-R), the National Survey of American Life (NSAL), and the National Latino and Asian American Study (NLAAS), ensuring that measures utilized yielded reliable and valid results across different subgroups.

The NCS-R data provides a pivotal component to the usability of the CPES by providing a sizable comparison group-White Americans, not sufficiently found in either of the other two datasets. Comparatively, a prominent feature of the NSAL was the oversampling of American Blacks and those of African or Caribbean descent [52]. The NLAAS is one of the most exhaustive studies of Hispanic and Asian Americans conducted [53]. All data was collected between 2001 and 2003; NLAAS surveys were available in multiple languages [52, 53].

\section{Outcome Measure}

The main outcome was lifetime occurrence of major depressive disorder (depression), a psychiatric condition described by the Diagnostic and Statistical Manual of Mental Disorders, Fourth Edition (DSM-IV) as "DSM-IV Major Depressive Disorder w/ hierarchy (Lifetime)." An individual was classified as having lifetime depression if all three criteria were met: (1) presence of a major depressive episode; (2) the major depressive episode is not better accounted for by schizoaffective disorder and is not superimposed on schizophrenia, schizophreniform disorder, delusional disorder, or psychotic disorder not otherwise specified; and (3) there has never been a manic episode, a mixed episode, or a hypomanic episode. The lifetime measure of major depressive disorder was selected to capture a range of time from initial arrival, early settlement, and establishment of residence, specifically for foreign-born individuals. Since the onset of depression often occurs between the ages of 30 and 44 [37], and the estimated age of migration is from about 29 to 36 years [38], this measure covered a range of years wherein foreign-born minorities may first encounter discrimination and may have lower levels of income.

\section{Independent Variables}

To assess the validity of the HME's application to depression, block 1 included race, ethnicity, and nativity. Race/ethnicity was measured with five dichotomous categories: (1) nonHispanic White (referent), (2) Asian, (3) Hispanic, (4) AfroCaribbean, and (5) Black. Nativity was measured with a single dummy variable: American-born (referent) or foreign-born.

Demographic measures included gender and age. Gender was represented by a single dummy variable (female $=1$; male $=0$ ). Age was grouped into five categories: (1) 18 to 28 years old (referent), (2) 29 to 40 years old, (3) 41 to 50 years old, (4) 51 to 59 years old, and (5) 60 years or over. Socioeconomic status incorporated another two measures: education and income. Level of education completed was measured at four incremental levels: (1) primary education, (2) high school graduate, (3) some college education, and (4) college graduate. Annual household income also leveraged four incremental classifications: (1) $\$ 0$ to $\$ 49,999$ per year (referent); (2) $\$ 50,000$ to $\$ 99,999$ per year; (3) $\$ 100,000$ to $\$ 149,999$ per year; and (4) greater than or equal to $\$ 150,000$ per year.

Healthy lifestyle factors were assessed through two variables: heavy alcohol use and cigarette smoking. To account for heavy alcohol consumption, we used a dummy variable ( $1=$ "yes" and $0=$ "no") that represented whether a respondent had ever met the criteria for the 
DSM-IV diagnosis of alcohol abuse in his/her lifetime, manifested by one (or more) of the following: within a 12-month period, (1) recurrent substance use resulting in a failure to fulfill major role obligations at work, school, or home; (2) recurrent alcohol use in situations in which it is physically hazardous; (3) recurrent alcohol-related legal problems, continued alcohol use despite having persistent or recurrent social or interpersonal problems caused or exacerbated by the effects of alcohol; or (4) the symptoms present have never met the criteria for an alcohol dependence diagnosis. To assess smoking status, we used a dummy variable $(1=$ yes and $0=$ no) that indicated whether the respondent smokes regularly. Although other tobacco use measures were available, this was selected due its statistical power. Furthermore, a current measure of smoking may represent a smoking response to discrimination or social disadvantage [43, 44].

Discrimination was represented by a composite measure constructed by averaging responses across five measures pertaining to how often respondents encountered discriminatory behavior, in their current situation, attributed to their race or ethnicity. The first item asked how often respondents were treated with less respect than other people, the second asked how often they were threatened or harassed, the third asked how often they were treated as dishonest, the fourth asked how often they were treated as less smart, and the final item asked how often they were called names or insulted. Responses were recorded on a 6-point scale: never (0), less than once a year (1), a few times a year (2), a few times a month (3), at least once a week (4), and almost every day (5).

\section{Analytic Tools}

Univariate statistics were used to describe variations among individuals in the dataset. The multivariate analysis was performed using logistic regression, which estimates the probability of meeting the criteria for the DSMIV disorder of lifetime major depressive disorder (depression). Measures were allocated into theoretical blocks and were entered into in a stepwise fashion to illustrate the impact of each set of measures and highlight shifts in explanatory power with the inclusion of each subsequent block. Five models were included. Race/ethnicity and nativity, which are central to this analysis, were included in model 1. SES and demographic variables were entered in model 2. Health lifestyle measures were entered in model 3 , since these variables are known to be correlated with socioeconomic and demographic measures entered previously. Model 4 included an index representing severity of discrimination. Finally, model 5 included nativity and race/ethnicity interactions.
Weighting of the CPES data is used in all univariate and multivariate analyses, as recommended by ICPSR (2009) to realign the data to national parameters, since the data has been oversampled for racial and ethnic minorities. All analyses were conducted with SAS version 9.3 software.

\section{Results}

Sample characteristics are found in Table 1. Approximately $16 \%$ of the weighted sample met the criteria for the DSM-IV disorder of lifetime major depressive disorder (depression). Thirty-four percent were White, $13 \%$ Asian, $20 \%$ Hispanic, $8 \%$ Afro-Caribbean, and $25 \%$ were Black. Twenty-nine percent were foreignborn. Additionally, $58 \%$ were female, and $49 \%$ were between the ages of 18 and 40,34\% between 41 and 59 , and $17 \%$ greater than or equal to 60 years old. Sixty-five percent of the sample had an average household income less than $\$ 50,000,23 \%$ had an annual household income between $\$ 50,000$ and $\$ 99,999$, and $12 \%$ had an annual household income of $\$ 100,000$ or greater. Of the health behaviors, $10 \%$ abused alcohol and $63 \%$ were smokers. The mean discrimination score was 0.85 .

The rate of lifetime major depressive disorder (depression) varied as a function of nativity in minorities. A lower percentage of foreign-born Asians met the criteria for depression as compared to American-born Asians (15.03 vs. $7.91 \%$ ). Similarly, a lower percentage of foreign-born Hispanics met the criteria than American-born Hispanics (19.46 vs. $14.42 \%$ ), and a lower percentage of foreign-born Afro-Caribbeans met the criteria for depression than American-born Afro-Caribbeans (15.54 vs. $6.68 \%)$. The lowest levels of depression were found in foreign-born Afro-Caribbeans followed by foreign-born Asians, providing directional support for the notion that nativity and depression are linked.

Table 2 provides the results of our multivariate analysis which implemented stepwise blocks reflecting five models in logistic regression. The $95 \%$ confidence intervals and odds ratios were included. Support was found for the HME; nativity was significant at the $p<0.001$ level. For each model, we measure the pseudo-R2 using the Tjur R2 since it is more similar to linear measures of fit and is not based on the likelihood function [54].

In model 1, immigrants had approximately $37 \%$ lower odds of meeting the criteria for depression as compared to those American-born (odds ratio $(\mathrm{OR})=0.632, p<0.001)$. Furthermore, all racial and ethnic groups were significantly less likely to meet the criteria for depression as compared to Whites. Asians and Afro-Caribbeans had approximately $50 \%$ lower odds and $54 \%$ lower odds, respectively, $(\mathrm{OR}=0.500, p<0.001$; 
Table 1 Sample characteristics and lifetime depression prevalence $(N=17,249)$

Frequency

(percentage)

\begin{tabular}{|c|c|}
\hline \multicolumn{2}{|l|}{ Race, ethnicity, nativity } \\
\hline Foreign-born & $4,996(28.96 \%)$ \\
\hline White & $5,981(34.67 \%)$ \\
\hline Asian & $2,211(12.82 \%)$ \\
\hline Hispanic & $3,369(19.53 \%)$ \\
\hline Afro-Caribbean & $1,449(8.40 \%)$ \\
\hline Black & $4,239(24.58 \%)$ \\
\hline \multicolumn{2}{|l|}{ Ethnicity/race and nativity } \\
\hline Asian, foreign-born & $1,732(10.04 \%)$ \\
\hline Hispanic, foreign-born & $1,920(11.13 \%)$ \\
\hline Afro-Caribbean, foreign-born & $1,063(6.16 \%)$ \\
\hline Black, foreign-born & $86(0.50 \%)$ \\
\hline With lifetime major depressive disorder (MDD) & $2,745(15.91 \%)$ \\
\hline \multicolumn{2}{|c|}{ MDD, Race/Ethnicity, and Nativity } \\
\hline White, American-born & $1,309(22.62 \%)$ \\
\hline Black, American-born & $487(11.72 \%)$ \\
\hline Black, foreign-born & $12(13.95 \%)$ \\
\hline Asian, American-born & $72(15.03 \%)$ \\
\hline Asian, foreign-born & $137(7.91 \%)$ \\
\hline Hispanic, American-born & $282(19.46 \%)$ \\
\hline Hispanic, Foreign-born & $277(14.42 \%)$ \\
\hline Afro-Caribbean, American-born & $60(15.54 \%)$ \\
\hline Afro-Caribbean, Foreign-born & $71(6.68 \%)$ \\
\hline \multicolumn{2}{|l|}{ Demographics } \\
\hline Female & $9,980(57.86 \%)$ \\
\hline Age $18-28$ & $3,775(21.89 \%)$ \\
\hline Age $29-40$ & $4,758(57.58 \%)$ \\
\hline Age $41-50$ & $3,231(18.73 \%)$ \\
\hline Age $51-59$ & $2,577(14.94 \%)$ \\
\hline Age $60+$ & $2,908(16.86 \%)$ \\
\hline \multicolumn{2}{|l|}{ Socioeconomic } \\
\hline Primary education & $3,570(20.70 \%)$ \\
\hline High school graduate & $5,061(29.34 \%)$ \\
\hline Some college & $4,523(26.22 \%)$ \\
\hline College graduate & $84,095(23.74 \%)$ \\
\hline Income less than $\$ 50,000(N / \%)$ & $11,228(65.09 \%)$ \\
\hline Income $\$ 50,000$ to $\$ 99,999(N / \%)$ & $3,930(22.78 \%)$ \\
\hline Income $\$ 100,000$ to $\$ 149,999(N / \%)$ & $1,184(6.86 \%)$ \\
\hline Income $\$ 150,000$ and greater $(N / \%)$ & $907(5.26 \%)$ \\
\hline \multicolumn{2}{|l|}{ Health lifestyles } \\
\hline Alcohol abuse & $1,659(10.13 \%)$ \\
\hline Smoking & $1,151(63.42 \%)$ \\
\hline \multicolumn{2}{|l|}{ Discrimination } \\
\hline $\begin{array}{l}\text { Discrimination scale (mean, standard } \\
\text { deviation) }\end{array}$ & $0.887,0.828$ \\
\hline
\end{tabular}

$\mathrm{OR}=0.464, p<0.001)$; Blacks had $55 \%$ lower odds $(\mathrm{OR}=0.457, p<0.001)$, and Hispanics had $14 \%$ lower odds of meeting the criteria for the disorder of depression relative to American-born Whites $(\mathrm{OR}=0.862$, $p<0.05$ ). After adjustments for demographic and socioeconomic differences, all race/ethnicities and foreignborn groups remain significantly less likely to meet the criteria for depression, further validating the HME.

Model 2, which included demographic and socioeconomic variables, was statistically significant. Females had approximately 2.2 times higher odds than males of meeting the criteria for depression after adjusting for other covariates $(\mathrm{OR}=2.199, p<0.001)$. Once adjusting for both health behaviors and the discrimination index, respondents with the age of 51-59 were $25 \%$ more likely to meet the criteria for depression $(\mathrm{OR}=1.248, p<0.01)$. Of the socioeconomic variables, only annual income had an association with depression. Relative to the lowest income level, all higher income categories had higher odds of meeting the criteria for depression, with the highest income category, $\$ 150,000$ per year and greater, having almost $30 \%$ higher odds of depression $(\mathrm{OR}=1.293, p<0.01)$.

The health lifestyle measures also provided insight. Controlling for other characteristics, smoking behavior and alcohol abuse were significant correlates of depression. Those who abuse alcohol had over two times the odds of having depression relative to those who did not $(\mathrm{OR}=2.146$, $p<0.001$ ), and smokers had about $13 \%$ higher odds of depression than those non-smokers $(\mathrm{OR}=1.315, p<0.001)$. Model 4 added the discrimination scale, which was statistically significant. The more frequently respondents were treated as dishonest, treated as less smart, treated with disrespect, threatened, or called names was associated with increases in the likelihood of meeting the criteria for depression $(\mathrm{OR}=$ $1.446, p<0.001)$.

The final model, model 5, included an interaction term of nativity with race/ethnicity to examine how the nativity and ethnicity combination is associated with meeting the criteria for depression. None were statistically significant except that between nativity and Afro-Caribbean ethnicity and between nativity and Asian race. Relative to American-born Whites, the adjusted odds of meeting the criteria for lifetime depression were 0.281 for foreign-born Afro-Caribbeans and 0.585 for American-born Afro-Caribbeans $(p<0.01)$. Likewise, relative to American-born Whites, the adjusted odds were 0.348 for foreign-born Asians and 0.585 for American-born Asians $(p<0.05)$. There were no significant interaction effects between nativity and race/ethnicity on meeting the criteria for lifetime depression for all other race/ethnic groups. The coefficient of discrimination, or Tjur R2, increases slightly with each successive model, indicating that latter models had marginally better predictive power for the data. 


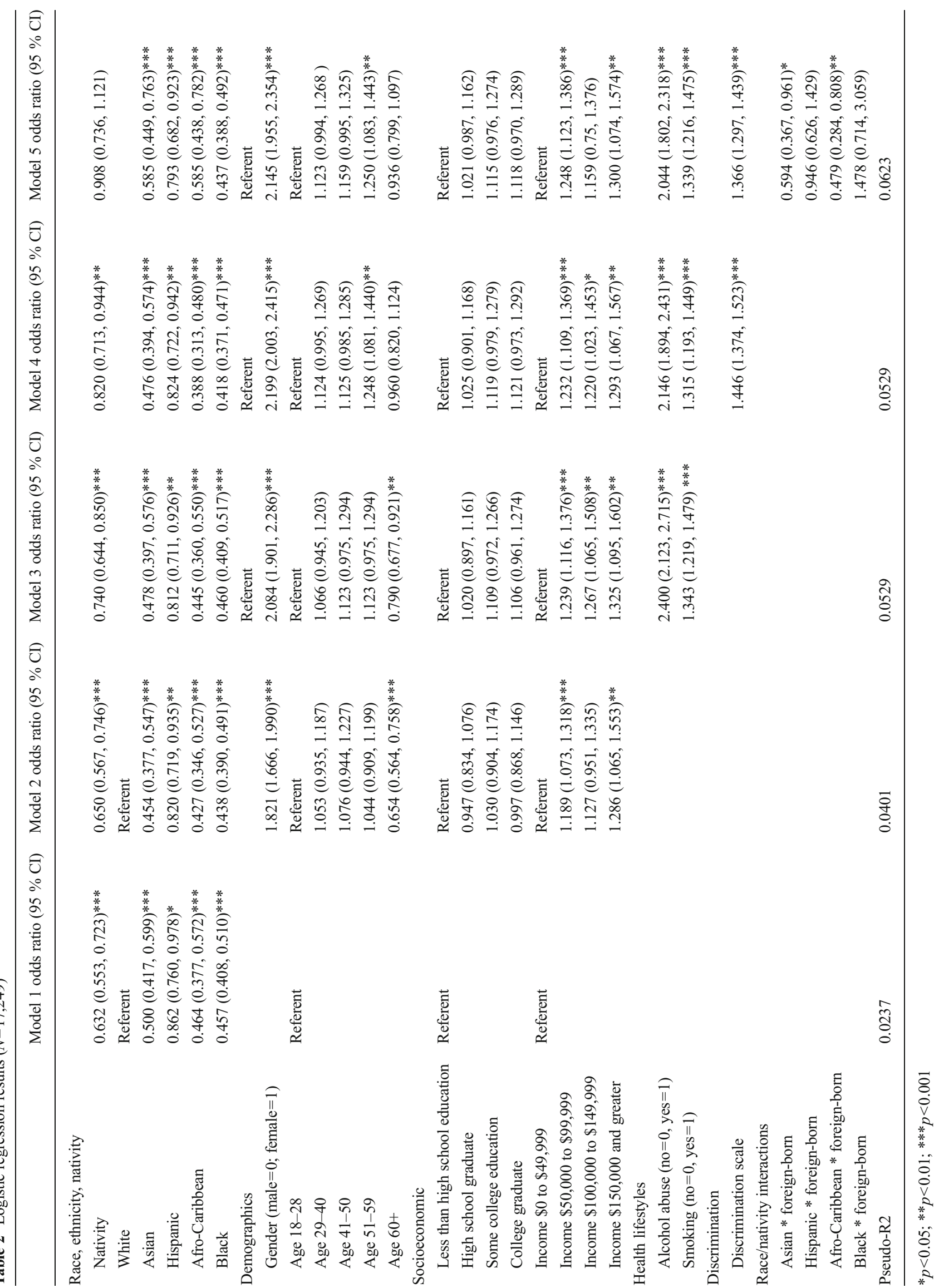




\section{Conclusion}

This study reveals that lifetime major depressive disorder (depression) is correlated with many measures and classifications discussed herein. Nativity was unilaterally protective. When interactions between race/ethnicity and nativity were evaluated, foreign-born Afro-Caribbeans and foreign-born Asians were found to exhibit lower rates of lifetime major depressive disorder, referred throughout as depression. A lower percentage of foreign-born Hispanics met the criteria for depression as compared to American-born Hispanics, but the interaction between nativity and Hispanic was not statistically significant when including discrimination, demographics, and SES. Income and education were associated with depression; higher levels of income and higher levels of education were correlated with higher rates of depression. As predicted, when discrimination was added to the model, the effect of nativity on depression was not as strong. This study, to the knowledge of the research team, reflects one of the few proactive applications of the Healthy Migrant Effect in research design and in combination with Health Lifestyle Theory to any mental health condition across a full set of racial and ethnic minorities.

\section{Limitations}

Three limitations should be noted, the first relating to the timing of this research project, the second pertaining to theoretical issues, and the last discussing quantitative issues and gaps.

First, the CPES was publically made available in 2007; however, the data was collected between 2001 and 2003. Over the last few years, immigration policies have become more stringent (e.g., HB56 in Alabama) affecting the way immigrants are perceived and treated. Second, the HME was formulated using Canadian culture and their immigration landscape, not those of the USA. Also, there are gaps in the HME in that it does not address the immigration pathway-legal or illegal, and the HME fails to directly account for socioeconomic factors. Lastly, since the CPES was a compilation of three datasets, slight differences in questions/verbiage caused measures to be eliminated from the joint dataset. Although many measures were available, some directly applicable information, such as neighborhood context, may have been available in one or two of the datasets, but not in all threethus, eliminated from this analysis.

\section{Future Research}

Although this research found a number of significant correlates with depression, questions remain over macro-level versus micro-level determinants. Fuwa [55] offered an analysis in which family attitudes were assessed to determine spatial location between very "traditional" and very egalitarian households in respect to opinions of both husband and wife. This in turn was used as a way to assess family structure. An analysis looking at depression which included family structure in addition to race/ethnicity and nativity may prove insightful, especially when attempting to decipher what forces play the largest role in impacting mental health outcomes. Also, performing an analysis of depressive outcomes which includes social support and thereby (potentially) resilience may yield relevant results.

Since immigration is a global phenomenon, replicating the design of this project (with appropriate adjustments) in other nations has the potential to inform the wider body of research. The subsequent information may assist governments, which offer nationalized health care, to prioritize immigrant health and may offer insight to social processes which affect the rates of mental illness in their countries.

In conclusion, support was found to confirm past findings around gender, discrimination, nativity, race, and ethnicity. Nativity did interact with ethnicity, race, and lifetime major depressive disorder. American-born persons, women, and those encountering discrimination had higher rates of depression. By using the Healthy Migrant Effect with Health Lifestyle Theory collaboratively and proactively, a more comprehensive design was adopted which produced these nuanced results, highlighting the impact of each factor individually and in combination with others.

Acknowledgments The authors would like to thank Dr. Shelia Cotten for her early guidance on the larger body of work, from which this manuscript was developed.

\section{Ethical Standard Statements}

Conflict of Interest Dr. Henna Budhwani, Dr. Kristine Ria Hearld, and Mr. Daniel Chavez-Yenter declare that they have no conflict of interest.

Informed Consent All procedures followed were in accordance with the ethical standards of the responsible committee on human experimentation (institutional and national) and with the Helsinki Declaration of 1975, as revised in 2000. Informed consent was obtained from all individuals for being included in the study.

\section{References}

1. U.S. Census Bureau. State and County QuickFacts. 2011. http:// quickfacts.census.gov/qfd/states/00000.html Retrieved March 24, 2014.

2. Passel JS, Cohn D. U.S. population projections: 2005-2050. Pew Research Center. 2008. http://pewsocialtrends.org/files/2010/10/85. pdf Retrieved May 28, 2014.

3. Morales LS, Kingston RS, Valdez RO, Escarce J. Socioeconomic, cultural, and behavioral factors affecting Hispanic health outcomes. J Health Care Poor Underserved. 2007;13(4):477-503. 
4. Perez C. Health status and health behaviour among immigrants. Health Reports Statistics Canada Catalogue, 2002;13(Supl.);82-003.

5. Scribner R. Paradox as paradigm - the health outcomes of Mexican Americans. Am J Public Health. 1996;86(3):303-5.

6. Kennedy S, McDonald JT, Biddle N. The healthy immigrant effect and immigrant selection: evidence from four countries. Australian Bureau of Statistics and Centre for Aboriginal Economic Policy Research. 2006;1-44. http://socserv.mcmaster.ca/sedap/p/sedap164. pdf Retrieved July 13, 2010.

7. Breslau J, Kendler KS, Su M, Gaxiola-Aguilar S, Kessler RC. Lifetime risk and persistence of psychiatric disorders across ethnic groups in the United States. Psychol Med. 2005;35(3):317-27.

8. McGuire TG, Miranda J. New evidence regarding racial and ethnic disparities in mental health: policy implications. Health Aff. 2008;27: 393-403.

9. Rosenfield S, Phillips J, White HR. Gender, race, and the self in mental health and crime. Soc Probl. 2006;53:161-85.

10. Williams D, Costa M, Leavell J. Race and mental health: patterns and challenges. In: Scheid TL, Brown TN, editors. A handbook for the study of mental health: social contexts, theories, and systems. New York: Cambridge University Press. pp 268-291.

11. Harris KM, Edlund MJ, Larson S. Racial and ethnic differences in the mental health problems and use of mental health care. Med Care. 2005;43:775-84.

12. Kohn LP, Hudson KM. Gender, ethnicity and depression: intersectionality and context in mental health research with African American women. Afr Am Res Perspect. 2002;8:174-84.

13. Lee J, Lei A, Sue S. The current state of mental health research on Asian Americans. J Hum Behav Soc Environ. 2001;3:159-78.

14. Norasakkunkit V, Kalick MS. Culture, ethnicity, and emotional distress measures: the role of self-construal and self-enhancement. J Cross-Cult Psychol. 2002;33:56-70.

15. Turner RJ, Gil AG. Psychiatric and substance use disorder in South Florida: racial/ethnic and gender contrasts in a young adult cohort. Arch Gen Psychiatry. 2002;59:43-50.

16. Williams D, Takeuchi D, Adair RK. Marital status and psychiatric disorders among blacks and whites. J Health Soc Behav. 1992;33: $140-57$.

17. Rosenfield S. Triple jeopardy? Mental health at the intersection of gender, race and class. Soc Sci Med. 2012;74:1791-801.

18. Roxburgh S. Untangling inequalities: gender, race, and socioeconomic differences in depression. Sociol Forum. 2009;24:357-81.

19. Spiegel JM, Yassi AL. Lessons from the margins of globalization: appreciating the Cuban health paradox. J Public Health Policy. 2004;25(10):85-110.

20. Finch BK, Kolody B, Vega WA. Perceived discrimination and depression among Mexican-origin adults in California. J Health Soc Behav. 2001;41(3):295-313.

21. Szalacha LA, Sumru E, Coll CG, Alarcón O, Fields JP, Ceder I. Discrimination and Puerto Rican children's and adolescents' mental health. Cult Divers Ethn Minor Psychol. 2003;9(2):141-55.

22. Pumariega A, Rothe E, Pumariega J. Mental health of immigrants and refugees. Community Ment Health J. 2005;41:581-93.

23. CDC Data \& Statistics. Feature: An estimated 1 in 10 U.S. adults report depression. 2011. http://www.cdc.gov/Features/dsDepression/ Retrieved March 14, 2014.

24. John DA, de Castro AB, Martin DP, Duran B, Takeuchi DT. Does an immigrant health paradox exist among Asian Americans? Associations of nativity and occupational class with self-rated health and mental disorders. Soc Sci Med. 2012;75(12):2085-98.

25. De Castro AB, Gee GC, Takeuchi DT. Examining alternative measures of social disadvantage among Asian Americans: the relevance of economic opportunity, subjective social status, and financial strain for health. J Immigr Minor Health. 2010;12(5):659-71.

26. Gavin AR, Walton E, Chae DH, Alegria M, Jackson JS, Takeuchi D. The associations between socio-economic status and major depressive disorder among Blacks, Latinos, Asians and nonHispanic Whites: findings from the Collaborative Psychiatric Epidemiology Studies. Psychol Med. 2010;40(1):51-61.

27. Kimbro RT, Bzostek S, Goldman N, Rodríguez G. Race, ethnicity, and the education gradient in health. Health Aff. 2008;27(2):361-72.

28. Leu J, Yen IH, Gansky SA, Walton E, Adler NE, Takeuchi DT. The association between subjective social status and mental health among Asian immigrants: investigating the influence of age at immigration. Soc Sci Med. 2008;66(5):1152-64.

29. Sánchez-Vaznaugh EV, Kawachi I, Subramanian SV, Sánchez BN, Acevedo-Garcia D. Do socioeconomic gradients in body mass index vary by race/ethnicity, gender, and birthplace? Am J Epidemiol. 2009;169(9):1102-12.

30. McGlade MS, Saha S, Dahlstrom ME. The Latina paradox: an opportunity for restructuring prenatal care delivery. Am J Public Health. 2004;94(12):2062-5.

31. Antonovsky A. Unraveling the mystery of health: how people manage stress and stay well. San Francisco: Jossey-Bass Inc. Publishers; 1967.

32. Illsley R, Baker D. Contextual variations in the meaning of health inequality. Soc Sci Med. 1991;32(4):359-65.

33. Cockerham WC. Sociology of mental disorder. Upper Saddle River: Pearson Prentice Hall; 2006.

34. LaVeist TA. Disentangling race and socioeconomic status: a key to understanding health inequalities. J Urban Health Bull N Y Acad Med. 2005;82(2 Supl.3):26-34.

35. Williams DR. Racial/ethnic variations in women's health: the social embeddedness of health. Am J Public Health. 2002;92(4):588-97.

36. Mościcki EK, Locke BZ, Rae DS, Boyd JH. Depressive symptoms among Mexican Americans: the Hispanic health and nutrition examination survey. Am J Epidemiol. 1989;130(2):348-60.

37. Kessler RC, Berglund P, Demler O, Jin R, Merikangas KR, Walters EE. Lifetime prevalence and age-of-onset distributions of DSM-IV disorders in the national comorbidity survey replication. Arch Gen Psychiatry. 2005;65:593-602.

38. Camarota SA. Immigrants in the United States, 2007: a profile of America's foreign-born population. Center for Immigration Studies. 2007. http://cis.org/immigrants_profile_2007 Retrieved June 19, 2014.

39. Jackson JS, Brown KT, Kirby DC. International perspectives on prejudice and racism. In: Eberha JL, Fiske ST, editors. Confronting racism: the problem and response. Thousand Oaks: Sage Publication; 1998. p. 101-35.

40. Lau AS, Tsai W, Shih J, Liu LL, Hwang WC, Takeuchi DT. The immigrant paradox among Asian American women: are disparities in the burden of depression and anxiety paradoxical or explicable? J Consult Clin Psychol. 2013;81(5):901-11.

41. Krieger N, Waterman PD, Kosheleva A, Chen JT, Carney DR, et al. Exposing racial discrimination: implicit \& explicit measures - the $m y$ body, my story study of 1005 US-born Black \& White community health center members. PLoS ONE. 2011;6(11):e27636. doi:10. 1371/journal.pone.0027636.

42. Pérez DJ, Fortuna L, Alegria M. Prevalence and correlates of everyday discrimination among US Latinos. J Community Psychol. 2008;36(4):421-33.

43. Cockerham WC. Health lifestyle theory and the convergence of agency and structure. J Health Soc Behav. 2005;46:51-67.

44. Caetano R, Clark CL, Tam T. Alcohol consumption among racial/ ethnic minorities. Alcohol Health Res World. 1998;22(4):233-41.

45. National Institute of Mental Health (NIMH). Expert panel addresses high rates of smoking in people with psychiatric disorders. 2009. http://www.nimh.nih.gov/science-news/2009/expert-paneladdresses-high-rates-of-smoking-in-people-with-psychiatricdisorders.shtml Retrieved June 27, 2010.

46. Arehart-Treichel J. Smoking and mental illness: which one's the chicken? 2003. PsychiartryOnline - Psychiatric News. http:// 
psychnews.psychiatryonline.org/newsarticle.aspx?articleid=106723 Retrieved on April 18, 2014.

47. Gilman SE, Abraham HD. A longitudinal study of the order of onset of alcohol dependence and major depression. Drug Alcohol Depend. 2001;63(3):277-86.

48. Nunes EV, Levin FR. Treatment of depression in patients with alcohol or other drug dependence. J Am Med Assoc. 2004;291: 1887-96.

49. Sullivan LE, Fiellin DA, O'Connor DG. The prevalence and impact of alcohol problems in major depression: a systematic review. Am J Med. 2004;118(4):330-41.

50. Blake SM, Ledsky R, Goodenow C, O'Donnell L. Recency of immigration, substance use, and sexual behavior among Massachusetts adolescents. Am J Public Health. 2001;91:794-8.
51. Lopez-Gonzalez L, Aravena VC, Hummer RA. Immigrant acculturation, gender and health behavior: a research note. Soc Forces. 2005;84(1):581-93.

52. Institute of Social Research. Overview: The National Survey of American Life. University of Michigan. 2010. http://www.rcgd.isr. umich.edu/prba/nsal Retrieved July 12, 2010.

53. Center for Multicultural Mental Health Research (CMMHR). Background and aims of the NLAAS. 2009. http://www. multiculturalmentalhealth.org/nlaas.asp Retrieved July 12, 2010.

54. Tjur T. Coefficients of determinations in logistics regression models - a new proposal: the coefficient of discrimination. Am Stat. 2009;63(4):366-72.

55. Fuwa M. Macro-level gender inequality and the division of household labor in 22 countries. Am Sociol Rev. 2004;69(6):751-67. 